\title{
The predicted value of Environment pollution treatment project investment based on the GM(1,1) model
}

\author{
Ai-qing Kou \\ International Business School \\ University of Finance and Economics \\ Kunming, China \\ 437805809@qq.com \\ Sun Meng* \\ International Business School
}

\author{
University of Finance and Economics \\ Kunming, China \\ 55658741@qq.com \\ Wei Zhou \\ School of Finance \\ University of Finance and Economics \\ Kunming, China \\ zw453@163.com
}

\begin{abstract}
The predicted value of Environment pollution treatment project investment is very significant in our country. It has less samples and uncertain information, a small dynamic sample prediction which is in view of the environmental pollution treatment project investment is very important .The GM(1,1) model is very appropriate. Combining with the classical GM(1,1) model through a process of accumulation of data, generating the immediate value sequence, constructing the grey whitening equation and selecting this project investment in our country over the 6 years as samples, fitting and forecasting the project and confirming the feasibility, practicality and veracity of the environmental pollution treatment project investment by combining with classic $G M(1,1)$ model has a certain guiding significance.
\end{abstract}

Keywords-GM (1,1) model; environmental pollution treatment project; investment

\section{INTRODUCTION}

Environmental problem is one of the most important problems which need to be focused on for a long time in our country. The nationwide haze weather reveals the serious situation of environmental pollution clearly since winter. We spent a large number of money in environment pollution treatment project investment every year and this project has a huge impact on the lives of our people. It's very important to do a more accurate prediction for it. It can not only make the national investment clear, but also make the money reasonable.

Zhang etc. analyzed the present situation and the trend of development of environment pollution treatment project investment in our country. They found that the total investment in China has a lot of growth. To prove us that the importance of environmental pollution treatment [1]. Cui etc. do a analysis for the project of local government from the social welfare goals [3]. Huang etc. put the environment and the environmental pollution treatment into a framework of endogenous growth and discussed the relationship of economic growth, environmental pollution and environmental pollution treatment by establishing an endogenous growth model of human capital [4]. Chen etc. did a research on industry pollution environment treatment investment and its relationship with economic normal based on panel data from 10 provinces and cities of our country in industrial pollution [2].

Because of the differential of the growth of our country's environment in different periods-embodied a new trend in a few years and the environment pollution treatment project investment is a small sample data-so we can use $\operatorname{GM}(1,1)$ model to do prediction research.

The grey system theory, created by the Chinese scholar Deng, is a new method of studying the problem of the less data poor information and uncertainty [16-17][19]. The research object of Grey system theory is uncertain systems as the 'partial information known, partial information unknown', 'small sample', 'poor information'. By extracting valuable information to the "part" of the known information generation and development, it achieves the correct description and effective monitoring to the behavior and evolution rule of system. In our world, 'small sample', 'poor information' decide a wide application field of the grey system the and the $\operatorname{GM}(1,1)$ model is the basis and core. Most foreign trade export macro forecast is based on logic judgment and qualitative analysis. Zou applied grey model to country foreign export trade and made a very good prediction [23]. Min compared grey prediction model, main factor and GDP based on time series regression model and provided scientific prediction method for talent [15]. Li etc. studied the $\operatorname{GM}(1,1)$ model Earlier in the housing forecast algorithm and did some adjustment and improvement about the algorithm of the model and reduced the error of the prediction [22]. As we all know, the real estate industry is an important factor which can influent the national economic condition and it also affected by many factors. It also applies to $\operatorname{GM}(1,1)$ model. Yao analyse thef Beijing's real estate investment by it. The traditional regression model is complex and requires data [12]. Ceng pointed out that the $\operatorname{GM}(1,1)$ model is simple, with less data, data and the predicted results can reflect the change trend of advantage [7]. Zhang put the specific development of Chinese

\footnotetext{
* Corresponding author
} 
animation industry as the research object. And she has made the forecast and send a prospect for country animation industry and provided the theoretical support through the $\operatorname{GM}(1,1)$ model [11]. Similarly, Ren made a prediction of the CPI economy with $\operatorname{GM}(1,1)$ model and also got good results [10]. Zhou etc. applied Generalized GM $(1,1)$ model to forecasting of fuel production and got a good result [16]. Liu told us the story of $\operatorname{GM}(1,1)$ model several basic forms and studied the nature and characteristics of different models [9]. He proved the equivalence relation between different models and their applicable scope. Lu etc. did evaluation and research to a number of energy-saving emission reduction policies in China through $\operatorname{GM}(1,1)$ and found that energy-intensive industry had a significant effect [13]. Using the Colombo stock data as an example, Liu etc. compared the grey prediction model with traditional prediction method [8]. It shows that grey prediction model is suitable for small samples. Zhou etc. used an improved metabolism grey model and predicted small samples with a singular datum and its application to sulfur dioxide emissions in China [17]. By fusing exponential buffer operator and its application, Zhou etc. improved grey model and made the model become more accurate [18].

Although a lot of people have done some research on our country's economic situation and investment situation of pollution control, $\operatorname{GM}(1,1)$ model has been widely used in various fields. But almost no one combine the two project investment to do prediction. The results of optimized $\operatorname{GM}(1,1)$ model were similar to classic $\operatorname{GM}(1,1)$ model, this paper will do a prediction about environmental pollution treatment project investment through the classic GM(1,1) model.

\section{THE RESEARCH METHODS}

Classic $\operatorname{GM}(1,1)$ prediction model is suitable for small sample data and which has the characteristics of simple calculation. This section will specifically address the $\operatorname{GM}(1,1)$ forecast model and its detailed operational steps.

\section{A. $\operatorname{GM}(1,1)$ predictive model}

The traditional grey prediction model is a one-time prediction based on a certain sample. The grey theory suggests that the system's behavior is nebulous, complex, but it is, after all, an ordered and integral function. The generation of grey Numbers is to find patterns in the clutter.

The grey model has some advantages:

a) you don't need a lot of samples.

b) the sample doesn't need to be distributed regularly.

c) the calculation is small.

d) quantitative analysis results are consistent with qualitative analysis.

e) it can be used for near-term, short-term and long-term forecasts.

\section{f) grey prediction has highly accurate.}

\section{B. Operation steps of $\operatorname{GM}(1,1)$ model}

This is a detailed description of the steps of the $\operatorname{GM}(1,1)$ model proposed by professor Deng.

Step 1: the original data is $X^{(0)}$, and exists: $X^{(0)}=\left(x^{(0)}(1), x^{(0)}(2), \ldots, x^{(0)}(n)\right)$
Among them, $x^{(0)}(k)^{3}, i=1,2, \ldots, n$

Step 2: build a sequence of accumulations (1-AGO) on the basis of non-negative data sequences $X^{(0)}=\left(x^{(0)}(1), x^{(0)}(2), \ldots, x^{(0)}(n)\right)$,

and the formula is as follows:

$X^{(1)}=\left(x^{(1)}(1), x^{(1)}(2), \ldots, x^{(1)}(n)\right)$

Among them:

$$
x^{(1)}(k)=\sum_{i=1}^{k} x^{(0)}(\mathrm{i})(k=1,2, \cdots, n)
$$

Step 3: based on the new data accumulation sequence, the sequence is generated by the next to production of the $Z^{(1)}$, which is the following formula:

$$
Z^{(1)}=\left(z^{(1)}(2), z^{(1)}(3), \ldots, z^{(1)}(n)\right)
$$

Among

them:

$$
z^{(1)}(k)=\frac{1}{2}\left(x^{(1)}(k)+x^{(1)}(k-1)\right), k=2,3, \cdots, n
$$

Step 4: construct the grey albino equation (also called the shadow equation), and take the parameter estimation, which is to estimate the method of the least square method to $X^{(0)}(k)+a Z^{(1)}(k)=b$, as follows:

If the estimation parameters make up a series of columns $\hat{a}=(\mathrm{a}, \mathrm{b})^{T}$,

$$
Y=\left[x^{(0)}(2), x^{(0)}(3), \ldots, x^{(0)}(n)\right]^{T}
$$

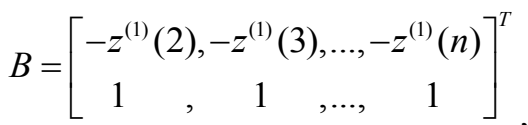

the least square method of $\operatorname{GM}(1,1)$ model $x^{(0)}(k)+a z^{(1)}(k)=b$

is satisfied with the estimate of the parameters:

$$
\alpha=(a, b)^{T}=\left(B^{T} B\right)^{-1} B^{T} Y
$$

We called $\frac{d x^{(1)}}{d t}+a x^{(1)}=b$ the white equation of $\operatorname{GM}(1,1)$ model. It also called the shadow equation.

Step 5: the solution $\frac{d x^{(1)}}{d t}+a x^{(1)}=b$ is also called a time response function.

$$
x^{(1)}(\mathrm{t})=\left(\hat{x}^{(1)}(1)-\frac{b}{a}\right) e^{-a k}+\frac{b}{a}
$$

Step 6: calculate the time response sequence, $\hat{x}^{(1)}(k+1)$, the formula is as follows:

$$
\begin{aligned}
& \hat{x}^{(1)}(k+1)=\left(x^{(0)}(1)-\frac{b}{a}\right) e^{-a k}+\frac{b}{a}, \\
& k=1,2, \cdots, n
\end{aligned}
$$

Step 7: recursively restore the time response sequence and find the original value $\hat{x}^{(0)}(k+1)$, the formula is as follows

$$
\begin{aligned}
& \hat{x}^{(0)}(k+1)=\alpha^{(1)} \hat{x}^{(1)}(k+1)=\hat{x}^{(1)}(k+1)-\hat{x}^{(1)}(k) \\
& =\left(1-e^{a}\right)\left(x^{(0)}(1)-\frac{b}{a}\right) e^{-a k}, k=1,2, \cdots, n
\end{aligned}
$$


The above is the prediction methods and steps for $\operatorname{GM}(1,1)$ model, $-\mathrm{a}$ is called development coefficient according to $\operatorname{GM}(1,1)$ model parameter, and $\mathrm{b}$ is grey action, -a reflects the trend development of $\hat{x}^{(1)}$ and $\hat{x}^{(0)}$.

\section{CASE ANALYSIS}

It's very appropriate to use Classic $\operatorname{GM}(1,1)$ prediction model on environmental pollution control investment prediction. The following will show $\operatorname{GM}(1,1)$ model's application on this project.

\section{A. Data acquisition and model calculation}

The following data is got from the national bureau of statistics of China in recent years(2008 2014) in environmental pollution treatment project investment. Select 2008-2013 environmental pollution treatment project investment as the modeling data, 2008 is the starting year and 2014 data is the model test data in Table 1.

TABLE I. INVESTMENT IN ENVIRONMENTAL POLLUTION CONTROL PROJECTS IN CHINA IN 2008-2014

\begin{tabular}{cccccccc}
\hline Year(unit:year) & 2008 & 2009 & 2010 & 2011 & 2012 & 2013 & 2014 \\
\hline Investment(unit:100million) & 4937.0 & 5258.4 & 7612.2 & 7114.0 & 8253.5 & 9037.2 & 9575.5
\end{tabular}

1) The raw data sequence is:

$$
X^{(0)}=\left(x^{(0)}(1), x^{(0)}(2), x^{(0)}(3), x^{(0)}(4), x^{(0)}(5), x^{(0)}(6)\right) \quad=
$$

$(4937.0,5258.4,7612.2,7114.0,8253.5,9037.2)$

2) On the basis of non-negative data sequences $X^{(0)}=\left(x^{(0)}(1), x^{(0)}(2), x^{(0)}(3), x^{(0)}(4), x^{(0)}(5), x^{(0)}(6)\right)$ us

e (2) to build a sequence of accumulative sequences (1-AGO), as follows:

$$
X^{(1)}=(4937.0,10195.4,17807.6 \text {, }
$$$$
24921.6,33175.1,42212.3)
$$

3) $B y(4)$,

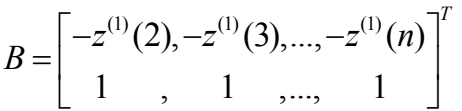

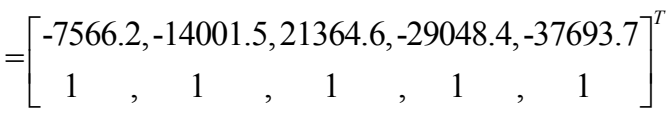

$Y=[5258.4,7612.2,7114.0,8253.5,9037.2)]^{T}$

B.The predicted value of Environment pollution treatment project investment
By counting, we can derive:

- $\mathrm{a}=-0.107486, \mathrm{~b}=5097.38, \mathrm{~b} / \mathrm{a}=-47423.77$, with $\mathrm{a}$ forecast of 10169.70, average relative error: 6.26.

We know that the $\operatorname{GM}(1,1)$ model requires development of classic coefficient $|\mathrm{a}|<2$, and the value of $\mathrm{a}$ is close to zero. he more accurate prediction results. This is very good for prediction of investment in environmental pollution control in China

Based on the $\operatorname{GM}(1,1)$ model, we predict the Environment pollution treatment project investment. We can get the investment forecast in 2014 is 10169.7. The actual value of it is 957.55 in 2014 . It can be seen that the $\operatorname{GM}(1,1)$ model for environmental pollution treatment project investment prediction has certain feasibility. Although the average relative error is a little big, the prediction results is also relatively accurate.

Fig. 1. is a graph of the investment of environmental pollution control projects in China in the past year, as follows.

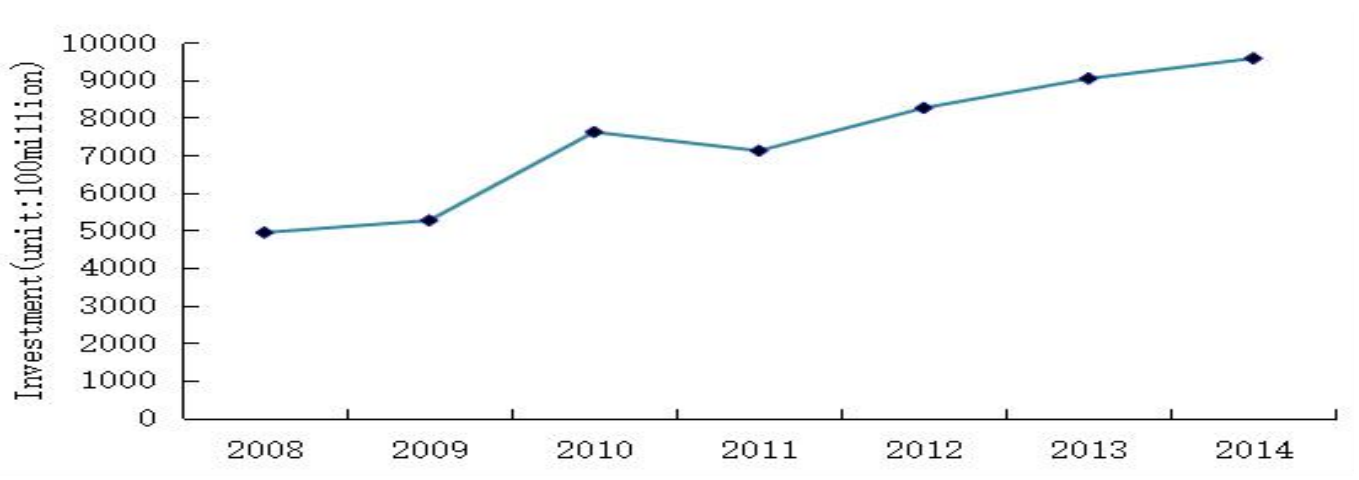

Fig. 1. From 2008 to 2014, China's investment in environmental pollution control projects

\section{CONCLUSIONS}

This paper makes a prediction of the Environment pollution treatment project investment based on $\operatorname{GM}(1,1)$ 
model, and the prediction results are feasible. This article picks up data from recent years, because it is not the more data you pick, the better. Environmental pollution situation in our country also has a very big change for a long time. Long historical stage forecasting result is bad instead. From the point of prediction results, the value of environmental pollution will rise slightly in 2014, and similar to the actual value. Therefore, this model has important theoretical significance and practical significance in the project research .

But the model applies only suit to short or medium-term forecasts, and there are some limits to long-term problems.

\section{ACKNOWLEDGMENT}

This work was supported by the Natural Science Foundation of China (No. 71561026), Science Foundation and Major Project of Educational Committee of Yunnan Province (Grant No. 2014Z100), and Philosophy and Social Science Foundation of Yunnan Province (Grant No. YB2015087).

\section{REFERENCES}

[1] K.M. Zhang, and R.Q. Sun, "Current situation and trend of development of China's environmental pollution control investment analysis," China environmental science, 1999, pp. 97-101

[2] S.H. Chen, S.Y. Xu, and Z.C. Yang, "China's industrial pollution environment relationship between investment and economic growth empirical research - 10 provinces and cities based on panel data analysis," Journal of scientific decision-making, 2015, pp. 43-54

[3] Y.F. Cui, and X.C. Liu, "China's local government environmental pollution control strategy game analysis between - based on the perspective of government social welfare goal," Journal of reform and development, 2009, pp. 62-65.

[4] J. Huang, and S.H. Chen, "Environmental pollution and economic growth: model and China's experience research," Nankai economic research, 2011, pp. 142-152

[5] S.F. Liu, Y.G. Dang, and Z.G. Fang, The grey system theory and its application (fifth edition), CA: Beijing science press, 2010.

[6] B.L. Duan, Q. Feng, and D.J. Liu, "Based on the grey GM $(1,1)$ model to predict the urban population scale, in DaTong city, for example," Journal of ShanXi agricultural university, 2016, pp. 35-38.

[7] B. Ceng, S.F. Liu, and Z.G. Fang, "The grey combination prediction model and its application," Journal of management science in China, 2009 , pp. 150-155. From the BBC, it's a new model for the development of a new model for predicting transportation
[8] C. Liu, T. Shu, and S. Chen, "An improved grey neural network model for predicting transportation disruptions," Expert Systems with Applications, 2015, pp. 331-340.

[9] S.F. Liu, B. Ceng, and J.F. Liu, "Several basic form of GM $(1,1)$ model and its scope of application research," Journal of systems engineering and electronics, 2014, pp. 501-508

[10] J.J. Ren, "The CPI economic forecast based on the $\operatorname{GM}(1,1)$ model," Method, 2012, pp. 75-76.

[11] C.F. Zhang, "The GM(1,1) model is used in the prediction of the development of animation industry in China," Knowledge jungle, 2010, pp. 156-157.

[12] C.Y. Yao, "The investment analysis of Beijing real estate based on the $\operatorname{GM}(1,1)$ model," Industrial and technical economy, 2007, pp. 69-71.

[13] M. Lu, and Y.Y. Li, "Based on $\operatorname{GM}(1,1)$ model of a number of energy conservation and emissions reduction policy evaluation research in China," Ecological economy, 2014, pp. 45-49.

[14] H.T. Chen, "Research and development of China's energy consumption forecast based on the $\operatorname{GM}(1,1)$ model," Mining research and development, 2007, pp. 77-79.

[15] X.L. Min, "Based on the grey prediction model $\operatorname{GM}(1,1)$ analysis," Technology management research, 2005, pp. 72-77

[16] W. Zhou, and J.M. He, "Generalized GM $(1,1)$ model and its application in forecasting of fuel production," Applied Mathematical Modelling, 2013, pp. 6234-6243.

[17] W. Zhou, and D.M. Zhang, "An improved metabolism grey model for predicting small samples with a singular datum and its application to sulfur dioxide emissions in China," Discrete Dynamics in Nature and Society, 2016, pp. 1-12

[18] W. Zhou, B.Q. Ding and Y. Zhang, "The improved grey model by fusing exponential buffer operator and its application," Journal of Intelligent and Fuzzy Systems, 2017, (On line)

[19] W. Zhou, and Z. Xu, "Generalized asymmetric linguistic term set and its application to qualitative decision making involving risk appetites," European Journal of Operational Research, 2016, pp. 610-621

[20] W. Zhou, "Dynamic and asymmetric contagion reactions of financial markets during the last subprime crisis," Computational Economics, 2016, DOI: 10.1007/s10614-016-9606-z.

[21] W. Zhou, and J. He, "Intuitionistic fuzzy geometric Bonferroni means and their application in multicriteria decision making," International Journal of Intelligent Systems, 2012, pp. 995-1019

[22] D.Y. Li, and Z.S. Ma, "Research on Algorithm of grey GM $(1,1)$ model in house price forecast," Industry Discussion, 2006, pp. 96-98

[23] J. Zou, and Z.X. Jiang, "Application based on grey system GM $(1,1)$ model in prediction of China's foreign trade export," International trade issues, 2004, pp. 27-30 